\title{
Greek Economic Policy Uncertainty: Does It Matter For Europe? Evidence From A Dynamic Connectedness Decomposition Approach
}

\author{
Nikolaos Antonakakis $^{\S, \dagger, *}$, David Gabauer ${ }^{\S, \uparrow}$, and Rangan Gupta $a^{\ddagger}$ \\ ${ }^{3}$ Business \& Management Department, Webster Vienna Private University, Praterstraße 23, 1020 Vienna, Austria. \\ ${ }^{\dagger}$ Economics \& Finance Subject Group, University of Portsmouth, Portsmouth Business School, Portland Street, \\ Portsmouth, PO1 3DE, United Kingdom. \\ 【 Institute of Applied Statistics, Johannes Kepler University, Altenbergerstraße 69, 4020 Linz, Austria. Tel: +43 7322468 \\ 6806. Email: david.gabauer@jku.at. \\ ¥Department of Economics, University of Pretoria, Pretoria, 0002 South Africa. \\ ${ }^{*}$ Corresponding author.
}

\begin{abstract}
This study examines the propagation mechanism of economic policy uncertainty shocks within Greece and between Greece and Europe over the period of January, 1998 and May, 2018. Further insights about the Greek-internal and external dynamics of economic policy uncertainty are provided by employing the recently developed dynamic connectedness decomposition approach of Gabauer and Gupta (2018). Our analysis reveals that Greek economic policy uncertainty is dominating the European economic policy uncertainty nearly permanently throughout the period of analysis. In particular, the Greek banking policy uncertainty (capital controls) and Greek currency policy uncertainty (Grexit rumours) have been significant net pairwise transmitters with respect to the European economic policy uncertainty. In addition, the Greek-internal transmission mechanism indicates that, Greek fiscal policy uncertainty indices are driven by Greek related monetary policy indices. Finally, our impulse response analysis suggests that the persistence of monetary policy related shocks is varying over time and increased after the Global Financial Crisis of 2007-2009. This magnifying effect explains partially the prolonged recovery of the European economy.
\end{abstract}

Keywords: TVP-VAR, Dynamic Connectedness, Dynamic Connectedness Decomposition, Categorical Economic Policy Uncertainty Spillovers

JEL codes: C32, C50, F42 


\section{Introduction}

In the wake of the Global Financial Crisis of 2007-2009, when the global economy was still reeling, recovery in Europe was delayed due to the Eurozone sovereign debt crisis (2010). While, the main root of this Eurozone crisis was in Greece, countries like Cyprus, Ireland, Italy, Portugal and Spain also had a role to play. These countries would have been unable to repay or refinance their government debt or to bail out over-indebted banks under their national supervision without the assistance of other Eurozone countries, the European Central Bank (ECB), and the International Monetary Fund (IMF).

The detailed causes of the European governmental debt crisis still tend to vary and to be interconnected. In several countries, private debts arising from a property bubble were transferred to sovereign debt as a result of banking system bailouts and government responses to slowing economies post-bubble. The structure of the eurozone as a currency union without fiscal union is believed to have contributed to the crisis and limited the ability of European leaders to respond. At the same time, European banks also tend to own a significant amount of sovereign debt, resulting in concerns regarding the solvency of banking systems, which in turn deepened the crisis.

The slow recovery of European countries and the aforementioned factors raised questions regarding the stability of the European currency union. Alesina et al. (1996); Chen and Feng (1996); Jong-A-Pin (2009) and Aisen and Veiga (2013) find that an increase in a country's political instability slows down its economic growth. Based on this linkage, this study tries to answer whether Greece has been the dominant driver of European political uncertainty and hence slowed down the European economic recovery or whether the European political uncertainty caused slow economic growth in Greece. To answer this question, we are analyzing the uncertainty transmission mechanism between Europe and Greece.

However, we are not the first who are interested in the spillovers and multiplier effects across uncertainties to explain economic performance. This field of research is already an important line in economics. Among others Castelnuovo et al. (2017); Gupta et al. (2019, 2018) and Antonakakis et al. (2018) have found that the uncertainties across economies are indeed interrelated. This means that, the overall domestic uncertainty is not only influenced by its within policy-related uncertainties, but also by external uncertainty spillovers. Note that understanding a country's uncertainty tranmission mechanism re- 
quires to differentiate between its internal and external policy uncertainty propagation processes. Thus, by taking into account both parts of the tranmsission mechanism, the direct and indirect (through the international feedback loop) impacts of uncertainty shocks can be evaluated. Keep in mind that a shock's prolonged effects are caused by the external spillovers magnified by the international feedback loop. This knowledge is of great importance for policy makers especially since it helps to create an 'early-warning system' (Diebold and Yılmaz, 2012) which allows to mitigate the adverse effects of spillovers by adjusting different political instruments. However, it is also essential to know which form of uncertainty plays a more dominant role (Mumtaz and Surico, 2018).

While studies like Ajmi et al. (2014); Biljanovska et al. (2017); Caggiano et al. (2017); Colombo (2013); Klößner and Sekkel (2014), and Yin and Han (2014) focus on the transmission mechanism of international economic policy uncertainty, others investigate uncertainty spillovers within the sovereign debt markets (see for example, Antonakakis et al., 2018; Apergis and Cooray, 2014; De Santis et al., 2018). However, the main focus so far is grounded on the investigation of country-level uncertainty propagation mechanism. Only recently Gabauer and Gupta (2018) analyze the uncertainty dynamics on a more granular level by examining categorical economic policy uncertainty spillovers between the US and Japan. In more detail, the employed categorical economic policy uncertainty indices have been monetary, fiscal, trade and currency policy uncertainty. This line of research gives further insights in the country-internal and external tranmission mechanism and provides us with further information about the international feedback loop, its magnification effect and the persistence of shocks across all analyzed countries in the network. This concept paired with the recently provided set of Greek categorical economic policy uncertainty indices (Hardouvelis et al., 2018) allows us to analyze the uncertainty transmission mechanism between Europe and Greece.

We believe that the investigation of the Greek country-internal and external uncertainty propagation mechanism and its impact on the European economy as a whole is of major importance for policy makers and to the best of our knowledge not examined so far. The estimated uncertainty propagation mechanism between Greece and Europe will reveal the transmitter of shocks and hence who is slowing down which economic recovery. In the case of Greece, we employ the recently developed Greek categorical economic policy uncertainty indices which will give us a more granular and detailed insight in the underyling uncertainty dynamics. The employed Greek categorical economic policy un- 
certainty series are related to the sovereign debt, banking, currency, tax, pension fund, and monetary policy. This examination should provide us with the following information: (i) whether the European economy or Greece is the net transmitter of uncertainty shocks, (ii) what is the direction and the impact of the Greek categorical economic policy uncertainty shocks, and (iii) how persistent particular uncertainty shocks are.

To the best of our knowledge, this study is the first that attempts to examine the uncertainty spillovers of various types of uncertainties within Greece and Europe, by taking advantage of the newly developed connectedness decomposition approach by Gabauer and Gupta (2018) which allows the calculation of country-internal and external transmission processes. Important to note is that this approach is an extension of the fully-fledged time-varying parameter vector autoregressive (TVP-VAR) connectedness approach of Antonakakis and Gabauer (2017) which in turn is based on the well-known dynamic connectedness approach of Diebold and Yılmaz (2014). Our chosen approach refines the measures of the initially proposed framework in many respects, since there is no need to arbitrarily set the rolling-window size, there is no loss of observations, and the results are not sensitive to outliers. Overall, this rather complex estimation procedure is chosen to estimate the time-varying internal and external tranmission mechanisms between Greece and Europe which will reveal whether the dynamics across the employed series are stable or influenced through the Global Financial Crisis or the European governmental debt crisis.

The results of our empirical analysis reveal that the economic policy uncertainty between Greece and Europe is bidirectional and that Greece is nearly throughout the whole sample the net transmitter of uncertainty. This can be explained in more detail by looking on the categorical level where we find that the Greek currency uncertainty and monetary uncertainty spillovers are net pairwise transmitter with respect to the European economic policy uncertainty. On the opposite, we find that the Greek pension uncertainty and Greek debt uncertainty are net receivers of shocks with respect to European economic policy uncertainty. However, the country-internal transmission mechanism reveals the fiscal policy uncertainty is overshadowed by shocks related monetary policy which explains why on the aggregated level the shocks have been transmitter from Greece to Europe. Finally, the impulse response analysis illustrates that monetary policy related uncertainty shocks are more persistent during the time of economic turmoils such as the Global Financial Crisis and the European governmental debt crisis. 
The remainder of this paper is organized as follows: Section 2 describes the data and the empirical methodology. The empirical results of our analysis are presented in Section 3, while Section 4 concludes the study.

\section{Data \& Methodology}

The dataset consists of monthly news-based economic policy uncertainty indices (EPU). The European economic policy uncertainty index (EEPU) is based on the work of Baker et al. (2016) whereas the Greek categorical EPU are provided by Hardouvelis et al. (2018) and cover banking (EPUB), currency (EPUC), taxes (EPUT), debt (EPUD), pension (EPUP), and monetary policy (EPUM). These indices rest on newspaper searches with term sets related to economy, policy and uncertainty. Our data ${ }^{1}$ spans over the period from January, 1998 to May, 2018.

In Figure 1, the raw EPU indices are visualized whereby certain amount of uncertainty co-movements of country-specific categorical uncertainty can be observed. Since, nearly all raw series of EPU are non-stationary, we use annual percentage changes, $y_{i t}=\log \left(x_{i t}\right)-$ $\log \left(x_{i t-12}\right)$ as illustrated in Figure 2.

[Insert Figures 1 and 2 around here]

Table 1 shows that all transformed series are significantly positively skewed, leptokurtic, not normally distributed, and stationary on the $1 \%$ significance level. Furthermore, all series are significantly autocorrelated on the $1 \%$ significance level and four out of seven variables exhibit significant $\mathrm{ARCH}$ errors at least on the $5 \%$ significance level which indicates that estimating a VAR model with a time-varying covariance-variance structure seems to be appropriate.

[Insert Table 1 around here]

\subsection{TVP-VAR-based Connectedness Approach}

As mentioned previously the summary statistics imply that a VAR model with a timevarying variance-covariance matrix would be adequate. In addition, we assume that the

\footnotetext{
${ }^{1}$ The data is available for download from: http://www.policyuncertainty.com/HKKS_Monthly. html and http://www.policyuncertainty.com/europe_monthly.html for Greece and Europe, respectively.
} 
relationship across the transformed uncertainty indices is varying with time. Thus, the propagation mechanism estimated by the connectedness approach of (Diebold and Yllmaz, 2014) will rest on a TVP-VAR model as outlined by Antonakakis and Gabauer (2017). According to the Bayesian information criterion (BIC), the TVP-VAR model should be estimated with one lag which can be written as,

$$
\begin{aligned}
& \boldsymbol{y}_{t}=\boldsymbol{\Phi}_{t} \boldsymbol{y}_{t-1}+\boldsymbol{u}_{t} \quad \boldsymbol{u}_{t} \mid \boldsymbol{\Omega}_{t-1} \sim N\left(\mathbf{0}, \boldsymbol{\Sigma}_{t}\right) \\
& \operatorname{vec}\left(\boldsymbol{\Phi}_{t}\right)=\operatorname{vec}\left(\boldsymbol{\Phi}_{t-1}\right)+\boldsymbol{\xi}_{t} \quad \boldsymbol{\xi}_{t} \mid \boldsymbol{\Omega}_{t-1} \sim N\left(\mathbf{0}, \boldsymbol{\Sigma}_{t}^{\Phi}\right)
\end{aligned}
$$

where $\boldsymbol{\Omega}_{t-1}$ stands for all information available up to $t-1, \boldsymbol{y}_{t}$ and $\boldsymbol{u}_{t}$ represent $m \times 1$ dimensional vectors and $\boldsymbol{\Phi}_{t}$ and $\boldsymbol{\Sigma}_{t}$ are $m \times m$ dimensional matrices. In addition, $\boldsymbol{\xi}_{t}$ and $\operatorname{vec}\left(\boldsymbol{\Phi}_{t}\right)$ are $m^{2} \times 1$ dimensional vectors and $\boldsymbol{\Sigma}_{t}^{\Phi}$ is an $m^{2} \times m^{2}$ dimensional matrix

The connectedness approach developed by Diebold and Yllmaz (2014) rests on generalized impulse response functions (GIRF) and generalized forecast error variance decompositions (GFEVD) invented by Koop et al. (1996) and Pesaran and Shin (1998). Both measures are based on the time-varying coefficient and time-varying variance-covariance matrices retrieved from the TVP-VAR. Thus, we are transforming the TVP-VAR to a TVP-VMA model using the Wold representation theorem, $\boldsymbol{y}_{t}=\sum_{i=1}^{p} \boldsymbol{\Phi}_{i t} \boldsymbol{y}_{t-i}+\boldsymbol{u}_{t}=$ $\sum_{j=1}^{\infty} \boldsymbol{\Lambda}_{j t} \boldsymbol{u}_{t-j}+\boldsymbol{u}_{t}$.

Using the GIRF instead of its orthorgonalized version has the main advantage that the results are not influenced by the variable ordering. With the GIRF, we calculate how large the impact of a shock in variable $i$ is on all other variables $j$. Thus, the impact is computed as the difference of the presence and the absence of a shock in variable $i$ 's $K$-step ahead forecast on all other variables $j$. Hence, the GIRFs $\left(\Psi_{i j, t}(K)\right)$ represent the $K$-step ahead forecast dynamics of all variables $j$ following a shock in variable $i$. Mathematically, this can be written as,

$$
\begin{aligned}
\operatorname{GIRF}_{t}\left(K, \sqrt{\Sigma_{i i, t}}, \boldsymbol{\Omega}_{t-1}\right) & =E\left(\boldsymbol{y}_{t+K} \mid \sqrt{\Sigma_{i i, t}}, \boldsymbol{\Omega}_{t-1}\right)-E\left(\boldsymbol{y}_{t+K} \mid \boldsymbol{\Omega}_{t-1}\right) \\
\boldsymbol{\Psi}_{i, t}(K) & =\Sigma_{i i, t}^{-\frac{1}{2}} \boldsymbol{\Lambda}_{K, t} \boldsymbol{\Sigma}_{t} \boldsymbol{v}_{i}
\end{aligned}
$$

where $\boldsymbol{v}_{i, t}$ is the selection vector with a one on the $i$ th position and zero otherwise.

Afterwards, we compute the GFEVD $\left(\psi_{i j, t}(K)\right)$ that can be interpreted as the forecast error variance share one variable explains on others. These variance shares are then 
normalised, so that each row sums up to one, meaning that all variables together explain $100 \%$ of variable's $i$ forecast error variance. Subsequently, the GFEVD is calculated by

$$
\psi_{i j, t}(K)=\frac{\sum_{t=1}^{K-1} \Psi_{i j, t}^{2}}{\sum_{j=1}^{m} \sum_{t=1}^{K-1} \Psi_{i j, t}^{2}} \quad \sum_{j=1}^{m} \psi_{i j, t}(K)=1 \quad \sum_{i, j=1}^{m} \psi_{i j, t}(K)=m
$$

Notably, the diagonal elements are the own-variance share (how much of the forecast error variance of variable $i$ is explained by its own lagged values) and the off diagonal elements (how much of the forecast error variance of variable $i$ is explained by the lagged values of variable $j$ ). Based on the GFEVD, we compute all other relevant connectedness measures in five steps to complete the connectedness table.

Step I: We are interested in the impact variable $i$ has on all other variables $j$. This is called total directional connectedness TO all others and is defined by,

$$
\Gamma_{i \rightarrow j, t}(K)=\frac{\sum_{j=1, i \neq j}^{m} \psi_{j i, t}(K)}{\sum_{j=1}^{m} \psi_{j i, t}(K)}
$$

Step II: We reverse the concept and compute the impact all variables $j$ have on variable $i$. This is called total directional connectedness FROM all others and can be calculated as follows,

$$
\Gamma_{i \leftarrow j, t}(K)=\frac{\sum_{j=1, i \neq j}^{m} \psi_{i j, t}(K)}{\sum_{i=1}^{m} \psi_{i j, t}(K)}
$$

Step III: We subtract equation (6) from (7) to obtain the net total directional connectedness measures, which represent the dominance of variable $i$ on the whole network.

$$
\Gamma_{i, t}(K)=\Gamma_{i \rightarrow j, t}(K)-\Gamma_{i \leftarrow j, t}(K)
$$

A positive (negative) value illustrates that variable $i$ is driving the network more (less) than being driven by it. Hence, variable $i$ is a net transmitter (receiver).

Step IV: The net total directional connectedness is broken down to the bilateral level to get further insights in the underlying bidirectional dynamics. The bidirectional dynamics are called net pairwise directional connectedness (NPDC) and can be computed as follows,

$$
N P D C_{i j}(K)=\psi_{j i t}(K)-\psi_{i j t}(K)
$$


Step V: Finally, we compute the interconnectedness of the network using the adjusted total connectedness index (TCI) of Gabauer (2018) which lies within [0,1] if $K \rightarrow \infty$. This measure is defined as follows,

$$
\Gamma_{t}(K)=\frac{\sum_{i=1}^{m} 1-\psi_{i i, t}(K)}{m-1}
$$

The lower (higher) the TCI the less (more) the network is interconnected. Moreover, a high value is usually associated with a risky network since a shock in one variable will influence other variables substantially. On the opposite, a low TCI indicates that every variable is only influenced by its own lagged values.

Since we want to examine the country-internal and external uncertainty transmission processes we are applying the connectedness decomposition approach of Gabauer and Gupta (2018). First, the connectedness table is rewritten in $k$ partitions, each partition representing one country:

$$
\boldsymbol{\psi}(K)=[\psi]_{i j, t}(K)=\left[\begin{array}{cccc}
\boldsymbol{D}_{11} & \boldsymbol{D}_{12} & \ldots & \boldsymbol{D}_{1 k} \\
\boldsymbol{D}_{21} & \boldsymbol{D}_{22} & \ldots & \boldsymbol{D}_{2 k} \\
\vdots & \vdots & \ddots & \vdots \\
\boldsymbol{D}_{k 1} & \boldsymbol{D}_{k 2} & \ldots & \boldsymbol{D}_{k k}
\end{array}\right]
$$

where $\boldsymbol{D}_{i i}$ represents the internal connectedness of country $i$ and $\boldsymbol{D}_{i j}$ represents the connectedness from country $j$ to country $i$. Moreover, for computing internal and external connectedness measures, we have to set $\operatorname{diag}\left(\boldsymbol{D}_{i i}\right)=0$ and calculate,

$$
\begin{aligned}
T O_{i j} & =\sum_{n=1}^{k} \boldsymbol{D}_{i j, n m} \\
F R O M_{i j} & =\sum_{m=1}^{k} \boldsymbol{D}_{j i, n m} \\
N E T_{i j} & =T O_{i j}-F R O M_{i j} \\
E X_{i j} & =\sum_{n=1}^{k} \sum_{m=1}^{k} \boldsymbol{D}_{i j, n m}-\sum_{n=1}^{k} \sum_{m=1}^{k} \boldsymbol{D}_{j i, n m}
\end{aligned}
$$

where $T O_{i j}, F R O M_{i j}$ and $N E T_{i j}$ are corresponding to the previous interpretations but on the country-level and $E X_{i j}$ is the net international connectedness or net external connectedness. 
Finally, the country-specific TCI, $\Gamma_{\kappa, t}(K)$, and the international TCI, $\Gamma_{x, t}(K)$, is computed as follows:

$$
\begin{aligned}
\Gamma_{\kappa, t}(K) & =\frac{\sum_{i \in \rho} 1-\psi_{i i, t}(K)}{m-1} \\
\Gamma_{x, t}(K) & =\Gamma_{t}(K)-\sum_{i=1}^{k} \Gamma_{\kappa, t}(K)
\end{aligned}
$$

where $\rho$ is a set of all variables associated with country $\kappa$.

\section{Empirical results}

\subsection{Dynamic Connectedness Table}

In Table 2, we report the averages of the dynamic connectedness measures based on the TVP-VAR methodology. Since the TCI is equal to $65.8 \%$ - this means that on average $65.8 \%$ of a shock in one variable is transmitted to all others - the analyzed network seems to be highly interconnecteed. Out of the $65.8 \%, 41.9 \%$ of the spillovers are Greece-internal ones whereas $23.9 \%$ of the spillovers are caused by Europe. In other wordes, approximately one-fourth of the entire network spillovers can be accounted to the international spillovers between Greece and Europe. This measure already indicates that there is a high bidirectional relationship across Greece and Europe which we would have expected in the first place.

We observe that spillovers of different types of uncertainty in Greece had greater influence on European economic policy uncertainty than vice-versa, with Greek banking uncertainty (related to the capital controls imposed in Greece in June 2015 in an attempt to avoid an uncontrolled bank run) and currency uncertainty (e.g. rumours about potential Grexit and adoption of a 'new Drachma') being at the epicenter of the transmission of uncertainty both within Greece and between Greece and Europe. These results are also supported by the estimated net directional connectedness measures. Specifically, within Greece, banking, currency, and monetary policy uncertainty are net transmitters of shocks, while debt, tax, and pension uncertainty are net receivers. Overall, uncertainty indices related to monetary policy (EPUC, EPUB and EPUM) seem to be internal net transmitters whereas those related to fiscal policy (EPUD, EPUT and EPUP) are internal net receiver of shocks. 
If we account for European economic policy uncertainty too, we observe that the Greek monetary policy uncertainty becomes a net receiver of shocks, while European economic policy uncertainty along with the remaining Greek subcategories of uncertainty are net receivers of shocks. This means that Greece has a larger influence on Europe than Europe has on Greece in terms of uncertainty.

[Insert Table 2 around here]

\subsection{Dynamic Total Connectedness and Market Risk}

Since the static TCI indicators are masking the underyling dynamics we continue with the dynamic total connectedness indices. Figure 3 illustrates time-variation of the overall TCI, the Greece-internal TCI and the external TCI. According to this figure, we observe that the value of the overall TCI fluctuates over time within a broad range, spanning approximately between $55 \%$ and $85 \%$ which in addition is also responsive to extreme economic events. In particular, the first peak can be observed around 2003-2004 when Greece admits fudging the euro entry and that the Greek budget deficit has never been below 3\% since 1999. The next peak can be observed during the Global Financial Crisis when Greece got downgraded because of its unsustainable high debts. In addition, the Greek government expected an increase in its deficit by around $9 \%$ only in 2009 . The third peak at the beginning of 2010 can be assigned to the fact that Greece failed to pursue the financial markets to be able to cut its debts. Furthermore, the IMF and Europe granted the first bailout package.

Interestingly, the international TCI jumps twice to a higher level, (i) when it came to light that Greece manipulated data to enter the Eurozone, and (ii) when the Global Financial Crisis hit the European economy. However, it seems that the international TCI comes back to its initial level during 2015 whereas the Greek internal TCI increased which may have been caused by the Greek bailout referendum and the capital controls in the summer of 2015. The last peak in mid-2016 can be assigned to the Brexit votum which increased the uncertainty in the European market.

[Insert Figure 3 around here] 


\subsection{Net Dynamic Connectedness}

Turning our attention to the interpretation of the dynamic net directional connectedness plots further strengthens our findings. According to Figure 4, Greek banking and currency policy uncertainty are the main net transmitters of shocks throughout the sample, with the later reaching peaks during the beginning of 2010. These peaks can be associated with the concerns related to a Grexit scenario and the introduction of a 'new Drachma'. Noteworthy is that in mid-2012 there is a sharp decline which could be linked to Draghi's "Whatever it takes"-speech which calmed financial market uncertainty. Nevertheless, the trend that currency uncertainty is a net transmitter seems to constantly increase which could signal upcoming fears that the European currency union is not as stable as it ought be. Furthermore, one peak in mid-2015 can be observed which could mark the Greek bailout referendum that increased uncertainty in financial markets since the majority of the Greek voters declined the bailout conditions of the IMF, the ECB, and the European commission (EC).

The three main net receivers of the Greek categorical uncertainty measures are pension, taxes and debt uncertainty. All three became substantial net receiver after the Gobal Financial Crisis occurred. This can be explained by the fiscal austerity program which was imposed on Greece to reduce its budget deficits and debts. It included, among others, a freeze in the salaries of all governmental employees, cuts in bonuses, overtime workers, and work-related travel expenses, in addition to the increased value-added-taxes.

Finally, and most importantly, Figure 4 also indicates that the European economic policy uncertainty is driven by the Greek uncertainty indices. Notably, the European economic policy uncertainty reaches three lows, (i) during the Global Financial Crisis, (ii) during the European governmental debt crisis, and (i) in 2015 which was marked by capital controls and the Greek bailout referendum.

[Insert Figure 4 around here]

\subsection{Internal and External Net Directional Connectedness}

Figure 5 and Figure 6 represent the external and internal NPDC measures, respectively, which strengthen our previous findings. Specifically, Figure 5 indicates that banking, currency, debt and monetary policy uncertainties are driving the European economic policy uncertainty, while the Greek pension and tax uncertainty is driven by European economic 
policy uncertainty. Since currency and banking policy highly depend on monetary policy, we argue that monetary policy related uncertainty indices seem to substantially influence the European economic policy uncertainty.

By contrast, Greek tax and pension uncertainty are dominated by the European economic policy uncertainty which can be related to the fiscal austerity program imposed on Greece. Both uncertainties belong to fiscal policy related uncertainties. The third fiscal policy related uncertainty, debt uncertainty, is driving the European economic policy uncertainty since it is threatening the stability of the Eurozone according to the Maastricht criteria. However, it seems that at the beginning of 2016, Europe managed to deal appropriately with the Greek budget deficit and started to influence debt more than being influenced by it.

The increase in the net transmission of the Greek banking and currency uncertainty in mid-2015 can be explained by the fact that financial markets feared the outcome of the Greek bailout referendum, whereas the subsequent decline in both values can be associated with how Europe dealed with the outcome. Noteworthy is that the largest net transmission comes from the Greek currency uncertainty right after the start of the European governmental debt crisis which initially raised the question whether the European monetary union can survive the aftermath the Global Financial Crisis. Finally, we want to refer to the net transmission power of the Greek debt uncertainty which is telling a very detailed story. It increased in its power when rumours about the Greek data manipulation incident occurred and started decreasing after the Global Financial Crisis went viral. The bailout packages reduced its power to a low level, from which it started to increase again until Greece requested another bailout aid in 2015.

The internal net directional connectedness measures shown in Figure 6 reveal the dominance of Greek currency, banking and, to some extent, monetary policy uncertainty in the Greece-internal transmission process. Note that tax, debt, and pension uncertainty indices (and hence fiscal policy uncertainty in general) are permanently net receivers of shocks. This implies that monetary policy related uncertainties dominate fiscal policy related uncertainties which is in-line with the results of Gabauer and Gupta (2018).

[Insert Figures 5 and 6 around here]

Finally, Figure 7 shows that the Greek economic policy uncertainty mainly dominates the European economic policy uncertainty throughout the analyzed sample. Three peaks 
can be observed, (i) during the subprime market crisis which substantially influenced the Greek debts via defaulted collateralized debt obligations and mortgage-backed securities, (ii) the start of the European governmental debt crisis and (iii) at the beginning of 2015 when Greece requested another bailout package.

[Insert Figure 7 around here]

\subsection{The Persistence of Uncertainty Shocks}

Last but not least, the generalized impulse responses presented in Figure 8 indicate that Greek currency, banking and monetary policy shocks had a long-lasting impact (at least six months) both internally and externally. During the Global Financial Crisis and the European governmental debt crisis, it can be noted that the GIRF are substantially higher in magnitude and persistence than before the Global Financial Crisis. This further indicates that Greek banking, currency, and monetary policy uncertainty shocks have strongly shaped the European economic policy uncertainty during and after the Global Financial Crisis.

[Insert Figure 8 around here]

\section{Conclusion}

In this study, we examine whether and which subcategories of Greek economic policy uncertainty caused changes in European economic policy uncertainty and vice versa. In more detail, our results reveal that the Greek economic policy uncertainty is - throughout the period of analysis - a net transmitter of shocks with respect to the European economic policy uncertainty.

Specifically, the Greek banking, currency, monetary and debt policy uncertainty have been identified as the main net transmitters of shocks with respect to the European economic policy uncertainty. This could be explained by several factors, such as the Greek data manipulation incident, Grexit rumours, the Greek bailout referendum, and capital controls. On the opposite, the European economic policy uncertainty is dominating the Greek tax and pension uncertainty. This could be explained by the fiscal austerity program which was imposed on Greece in order to receive financial support. Greeceinternal spillovers have illustrated that fiscal policy related uncertainties are dominated 
by monetary policy related uncertainties. This result supports the finding of Gabauer and Gupta (2018). Finally, the GIRFs have shown that the uncertainty spillovers increased significantly in magnitude and persistence during times of economic turmoil which in turn prolonged the economic recovery in Europe as well.

From a policy perspective, given that the monetary and currency policies cannot be flexible for Greece with it being part of the Eurozone, changes need to be carried out in the banking sector and how government government debt is managed. In this regard, Piketty (2019) has suggested the need for a conference on all of Europe's debts, just like after World War II. He suggested that a restructuring of all debt, not just in Greece but in several European countries (Spain, Portugal, Italy and Ireland), is required. Further realizing that the ability to pay its debts depends greatly on the amount of tax the government is able to collect, tax reform measures and corruption leading to tax evasion also needs to be tackled, given Greece's high tax evasion rates. Finally, as highlighted by Stournaras (2018), enhanced supervisory framework needs to be developed and implemented in a rigorous manner for the management of non-performing exposures for banks. In essence strong supervisin of the banking structure and continuous fiscal austerity measures for long spans are required to put Greece on track, and prevent uncertainty spillovers to the other European economies.

In the wake of the recent US-China trade war, a similar study can be conducted, whereby one could analyze the impact of trade related uncertainties in US and China (as also developed by Baker et al. (2016), and Davis et al. (2019) ) on general economic uncertainty of other major developed and developing economies. An additional avenue, that we leave for future research is to investigate whether the aforementioned spillovers differ between expansions and contractions using an asymmetric extension of the TVPVAR-based spillover index. 


\section{References}

Aisen, A. and Veiga, F. J. (2013). How Does Political Instability Affect Economic Growth? European Journal of Political Economy, 29:151-167.

Ajmi, A. N., Gupta, R., and Kanda, P. (2014). Causality Between Economic Policy Uncertainty Across Countries: Evidence From Linear And Nonlinear Tests. Frontiers in Finance and Economics, 11(1):73-102.

Alesina, A., Özler, S., Roubini, N., and Swagel, P. (1996). Political Instability And Economic Growth. Journal of Economic Growth, 1(2):189-211.

Anscombe, F. J. and Glynn, W. J. (1983). Distribution Of The Kurtosis Statistic B2 For Normal Samples. Biometrika, 70(1):227-234.

Antonakakis, N. and Gabauer, D. (2017). Refined Measures Of Dynamic Connectedness Based On TVP-VAR. Technical report, University Library of Munich, Germany.

Antonakakis, N., Gabauer, D., Gupta, R., and Plakandaras, V. (2018). Dynamic Connectedness Of Uncertainty Across Developed Economies: A Time-Varying Approach. Economics Letters, 166:63-75.

Apergis, N. and Cooray, A. (2014). Convergence In Sovereign Debt Ratios Across Heavily Indebted EU Countries: Evidence From Club Convergence. Applied Economics Letters, 21(11):786-788.

Baker, S. R., Bloom, N., and Davis, S. J. (2016). Measuring Economic Policy Uncertainty. Quarterly Journal of Economics, 131(4):1593-1636.

Biljanovska, N., Grigoli, F., and Hengge, M. (2017). Fear Thy Neighbor: Spillovers From Economic Policy Uncertainty. IMF Working Papers 17/240, International Monetary Fund.

Caggiano, G., Castelnuovo, E., and Figueres, J. M. (2017). Economic Policy Uncertainty Spillovers In Booms And Busts. Technical report, CESifo Group Munich.

Castelnuovo, E., Lim, G., and Pellegrino, G. (2017). A Short Review Of The Recent Literature On Uncertainty. Australian Economic Review, 50(1):68-78.

Chen, B. and Feng, Y. (1996). Some Political Determinants Of Economic Growth: Theory And Empirical Implications. European Journal of Political Economy, 12(4):609-627.

Colombo, V. (2013). Economic Policy Uncertainty In The US: Does It Matter For The Euro Area? Economics Letters, 121(1):39-42.

D'Agostino, R. B. (1970). Transformation To Normality Of The Null Distribution Of G1. Biometrika, 57(3):679-681.

Davis, S., Liu, D., and Sheng, X. (2019). Economic Policy Uncertainty In China Since 1949: The View From Mainland Newspapers. Technical report.

De Santis, R. A., Zimic, S., et al. (2018). Spillovers Among Sovereign Debt Markets: Identification Through Absolute Magnitude Restrictions. Journal of Applied Econometrics, 33(5):727-747.

Diebold, F. X. and Yılmaz, K. (2012). Better To Give Than To Receive: Predictive Directional Measurement Of Volatility Spillovers. International Journal of Forecasting, 28(1):57-66.

Diebold, F. X. and Yllmaz, K. (2014). On The Network Topology Of Variance Decompositions: Measuring The Connectedness Of Financial Firms. Journal of Econometrics, 182(1):119-134.

Elliott, G., Rothenberg, T. J., and Stock, J. (1996). Efficient Tests For An Autoregressive Unit Root. Econometrica, 64(4):813-36.

Gabauer, D. (2018). 'To Be Or Not To Be' A Member Of An Optimum Currency Area? New Evidence From The ERM I Period. Technical report. 
Gabauer, D. and Gupta, R. (2018). On The Transmission Mechanism Of Country-Specific And International Economic Uncertainty Spillovers: Evidence From A TVP-VAR Connectedness Decomposition Approach. Economics Letters, 171:63-71.

Gupta, R., Lau, C. K. M., and Wohar, M. E. (2019). The Impact Of US Uncertainty On The Euro Area In Good And Bad Times: Evidence From A Quantile Structural Vector Autoregressive Model. Empirica, 46(2):353-368.

Gupta, R., Ma, J., Risse, M., and Wohar, M. E. (2018). Common Business Cycles And Volatilities In US States And MSAs: The Role Of Economic Uncertainty. Journal of Macroeconomics, 57:317-337.

Hardouvelis, G. A., Karalas, G., Karanastasis, D., and Samartzis, P. (2018). Economic Policy Uncertainty, Political Uncertainty And The Greek Economic Crisis. Technical report.

Jarque, C. M. and Bera, A. K. (1980). Efficient Tests For Normality, Homoscedasticity And Serial Independence Of Regression Residuals. Economics Letters, 6(3):255-259.

Jong-A-Pin, R. (2009). On The Measurement Of Political Instability And Its Impact On Economic Growth. European Journal of Political Economy, 25(1):15-29.

Klößner, S. and Sekkel, R. (2014). International Spillovers Of Policy Uncertainty. Economics Letters, 124(3):508-512.

Koop, G. and Korobilis, D. (2013). Large Time-Varying Parameter VARs. Journal of Econometrics, 177(2):185-198.

Koop, G. and Korobilis, D. (2014). A New Index Of Financial Conditions. European Economic Review, 71:101-116.

Koop, G., Pesaran, M. H., and Potter, S. M. (1996). Impulse Response Analysis In Nonlinear Multivariate Models. Journal of Econometrics, 74(1):119-147.

Ljung, G. M. and Box, G. E. (1978). On A Measure Of Lack Of Fit In Time Series Models. Biometrika, 65(2):297-303.

Mumtaz, H. and Surico, P. (2018). Policy Uncertainty And Aggregate Fluctuations. Journal of Applied Econometrics, 33(3):319-331.

Pesaran, H. H. and Shin, Y. (1998). Generalized Impulse Response Analysis In Linear Multivariate Models. Economics Letters, 58(1):17-29.

Piketty, T. (2019). 1789-2019, The Return Of Debt.

Stournaras, Y. (2018). Monetary Policy And Bank Supervision In Europe After The Last Financial And Sovereign Debt Crisis And Challenges For The Future. Technical report.

Yin, L. and Han, L. (2014). Spillovers Of Macroeconomic Uncertainty Among Major Economies. Applied Economics Letters, 21(13):938-944. 
Table 1: Summary Statistics

\begin{tabular}{|c|c|c|c|c|c|c|c|}
\hline & EEPU & EPUC & EPUB & EPUD & EPUT & EPUM & EPUP \\
\hline Mean & 0.118 & 0.152 & 0.087 & 0.232 & 0.09 & 0.128 & 0.177 \\
\hline Variance & 0.225 & 0.581 & 0.267 & 1.25 & 0.215 & 0.503 & 0.458 \\
\hline Skewness & $\begin{array}{c}1.253 * * * \\
(0.000)\end{array}$ & $\begin{array}{c}2.228 * * * \\
(0.000)\end{array}$ & $\begin{array}{c}1.461 * * * \\
(0.000)\end{array}$ & $\begin{array}{c}5.886 * * * \\
(0.000)\end{array}$ & $\begin{array}{c}1.708 * * * \\
(0.000)\end{array}$ & $\begin{array}{c}2.038 * * * \\
(0.000)\end{array}$ & $\begin{array}{c}1.284 * * * \\
(0.000)\end{array}$ \\
\hline Kurtosis & $\begin{array}{c}2.048 * * * \\
(0.000)\end{array}$ & $\begin{array}{c}7.919 * * * \\
(0.000)\end{array}$ & $\begin{array}{c}3.077 * * * \\
(0.000)\end{array}$ & $\begin{array}{c}46.332 * * * \\
(0.000)\end{array}$ & $\begin{array}{c}5.928 * * * \\
(0.000)\end{array}$ & $\begin{array}{c}5.415 * * * \\
(0.000)\end{array}$ & $\begin{array}{c}1.537 * * * \\
(0.001)\end{array}$ \\
\hline $\mathrm{JB}$ & $\begin{array}{c}101.639 * * * \\
(0.000)\end{array}$ & $\begin{array}{c}801.608 * * * \\
(0.000)\end{array}$ & $\begin{array}{c}174.770 * * * \\
(0.000)\end{array}$ & $\begin{array}{c}22185.650 * * * \\
(0.000)\end{array}$ & $\begin{array}{c}454.434 * * * \\
(0.000)\end{array}$ & $\begin{array}{c}445.985 * * * \\
(0.000)\end{array}$ & $\begin{array}{c}86.998 * * * \\
(0.000)\end{array}$ \\
\hline ERS & $\begin{array}{c}-3.462 * * * \\
(0.001)\end{array}$ & $\begin{array}{c}-4.676 * * * \\
(0.000)\end{array}$ & $\begin{array}{c}-3.970 * * * \\
(0.000)\end{array}$ & $\begin{array}{c}-5.400 * * * \\
(0.000)\end{array}$ & $\begin{array}{c}-5.772 * * * \\
(0.000)\end{array}$ & $\begin{array}{c}-5.719 * * * \\
(0.000)\end{array}$ & $\begin{array}{c}-4.869 * * * \\
(0.000)\end{array}$ \\
\hline$Q(5)$ & $\begin{array}{c}192.747 * * * \\
(0.000)\end{array}$ & $\begin{array}{c}175.783 * * * \\
(0.000)\end{array}$ & $\begin{array}{c}110.927 * * * \\
(0.000)\end{array}$ & $\begin{array}{c}31.061 * * * \\
(0.000)\end{array}$ & $\begin{array}{c}35.894 * * * \\
(0.000)\end{array}$ & $\begin{array}{c}55.147 * * * \\
(0.000)\end{array}$ & $\begin{array}{c}49.884 * * * \\
(0.000)\end{array}$ \\
\hline$Q^{2}(5)$ & $\begin{array}{c}46.003 * * * \\
(0.000)\end{array}$ & $\begin{array}{c}19.053 * * * \\
(0.002)\end{array}$ & $\begin{array}{c}44.972 * * * \\
(0.000)\end{array}$ & $\begin{array}{c}0.792 \\
(0.978)\end{array}$ & $\begin{array}{c}6.300 \\
(0.278)\end{array}$ & $\begin{array}{c}2.545 \\
(0.770)\end{array}$ & $\begin{array}{c}11.538 * * \\
(0.042)\end{array}$ \\
\hline \multicolumn{8}{|c|}{ Unconditional Correlations } \\
\hline & EEPU & EPUC & EPUB & EPUD & EPUT & EPUM & EPUP \\
\hline EEPU & 1.000 & 0.417 & 0.508 & 0.370 & 0.359 & 0.366 & 0.248 \\
\hline EPUC & 0.417 & 1.000 & 0.683 & 0.516 & 0.417 & 0.393 & 0.370 \\
\hline EPUB & 0.508 & 0.683 & 1.000 & 0.497 & 0.475 & 0.563 & 0.484 \\
\hline EPUD & 0.370 & 0.516 & 0.497 & 1.000 & 0.510 & 0.429 & 0.331 \\
\hline EPUT & 0.359 & 0.417 & 0.475 & 0.510 & 1.000 & 0.319 & 0.362 \\
\hline EPUM & 0.366 & 0.393 & 0.563 & 0.429 & 0.319 & 1.000 & 0.177 \\
\hline EPUP & 0.248 & 0.370 & 0.484 & 0.331 & 0.362 & 0.177 & 1.000 \\
\hline
\end{tabular}

Notes: $* * *, * * *$ denote significance at 1\%, $5 \%$ and $10 \%$ significance level; Skewness: D'Agostino (1970) test; Kurtosis: Anscombe and Glynn (1983) test; JB: Jarque and Bera (1980) normality test; ERS: Elliott et al. (1996) unit-root test; Q(5) and $Q^{2}(5)$ : Ljung and Box (1978) portmanteau test. EEPU = European Economic Policy, EPUB = Banking Policy, $\mathrm{EPUC}=$ Currency Policy, EPUT $=$ Tax Policy, EPUD $=$ Debt Policy, EPUP $=$ Pension Policy and EPUM $=$ Monetary Policy Uncertainty.

Table 2: Dynamic Connectedness Table

\begin{tabular}{lrrrrrrrrr}
\hline \hline & EEPU & EPUC & EPUB & EPUD & EPUT & EPUM & EPUP & FROM & FROM \\
\hline EEPU & 45.5 & 12.4 & 14.6 & 10.0 & 5.5 & 8.9 & 3.2 & & 54.5 \\
EPUC & 9.8 & 41.3 & 17.6 & 10.1 & 5.5 & 10.2 & 5.4 & 48.9 & 58.7 \\
EPUB & 10.6 & 18.6 & 33.5 & 9.3 & 7.2 & 13.5 & 7.5 & 56.0 & 66.5 \\
EPUD & 7.5 & 14.1 & 11.9 & 39.0 & 11.3 & 10.0 & 6.1 & 53.5 & 61.0 \\
EPUT & 7.2 & 9.6 & 10.5 & 12.4 & 46.2 & 7.5 & 6.6 & 46.6 & 53.8 \\
EPUM & 7.6 & 10.4 & 18.4 & 8.9 & 4.7 & 47.5 & 2.5 & 44.9 & 52.5 \\
EPUP & 4.6 & 12.0 & 13.9 & 7.2 & 7.0 & 3.3 & 52.0 & 43.4 & 48.0 \\
\hline$T O_{i}$ & & 64.7 & 72.3 & 47.8 & 35.8 & 44.6 & 28.1 & $T C I_{i}$ & $T C I_{x}$ \\
$N E T_{i}$ & & 15.8 & 16.3 & -5.7 & -10.8 & -0.3 & -15.3 & 41.9 & 23.9 \\
\hline$T O$ & 47.2 & 77.1 & 86.9 & 57.8 & 41.3 & 53.5 & 31.3 & & $T C I$ \\
$N E T$ & -7.3 & 18.4 & 20.4 & -3.2 & -12.5 & 1.0 & -16.7 & & 65.8 \\
NPSO & 2.0 & 6.0 & 5.0 & 3.0 & 1.0 & 4.0 & 0.0 & & \\
\hline
\end{tabular}

Notes: Values reported are variance decomposition shares for estimated TVP-VAR model with a lag length of order 1 according to the BIC. The variance decompositions are based on 12-step-ahead forecasts. Light grey highlighted cells indicate connectedness within Greece, while dark grey highlighted ones denote connectedness between Greece and Europe.

EEPU = European Economic Policy, EPUB = Banking Policy, EPUC = Currency Policy, EPUT = Tax Policy, $\mathrm{EPUD}=$ Debt Policy, EPUP $=$ Pension Policy and EPUM = Monetary Policy Uncertainty. 
Figure 1: Raw Series

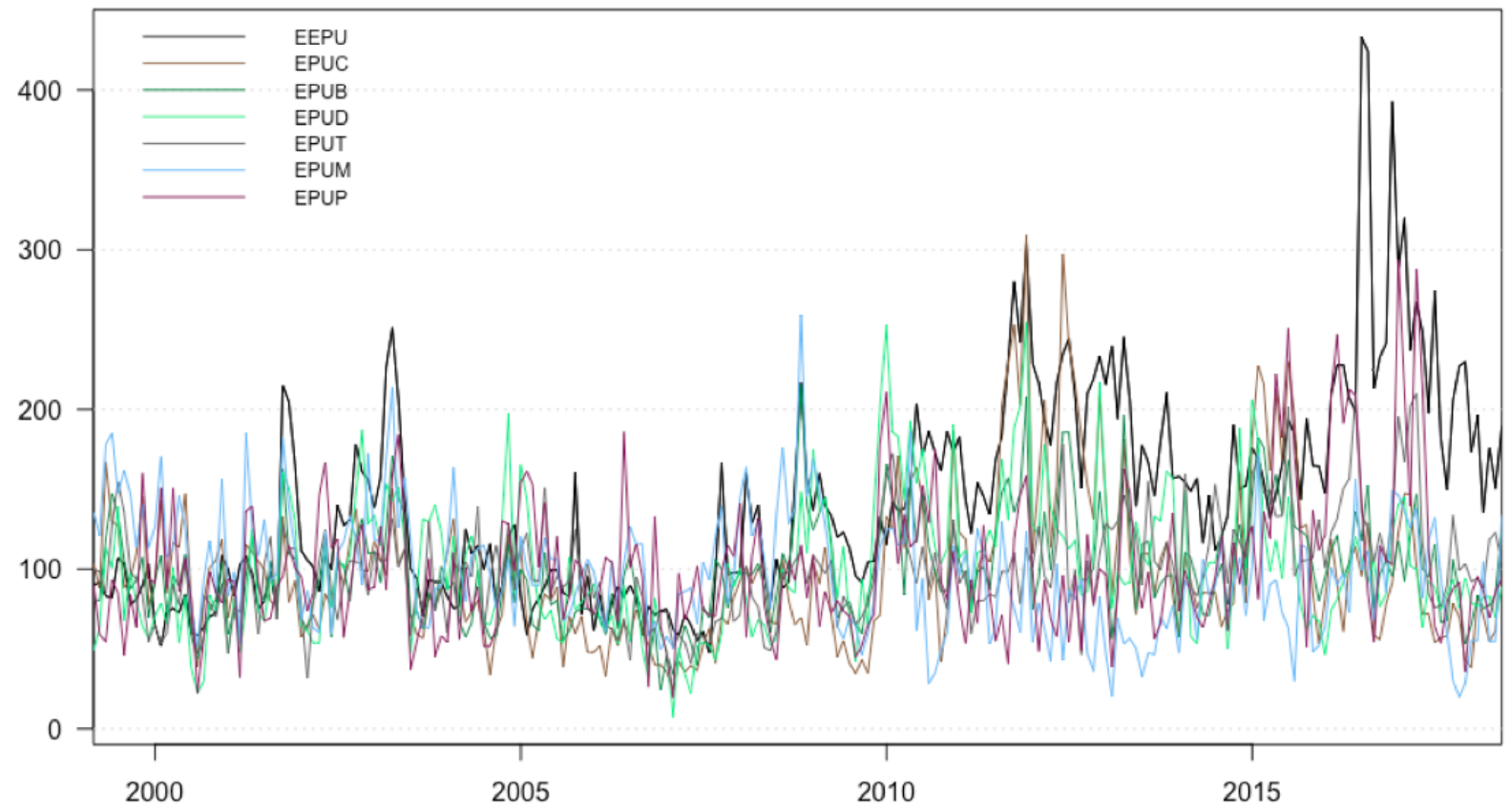

Notes: EEPU = European Economic Policy, EPUB = Banking Policy, EPUC = Currency Policy, $\mathrm{EPUT}=$ Tax Policy, EPUD $=$ Debt Policy, EPUP $=$ Pension Policy and EPUM $=$ Monetary Policy Uncertainty.

Figure 2: Annual Percentage Changes

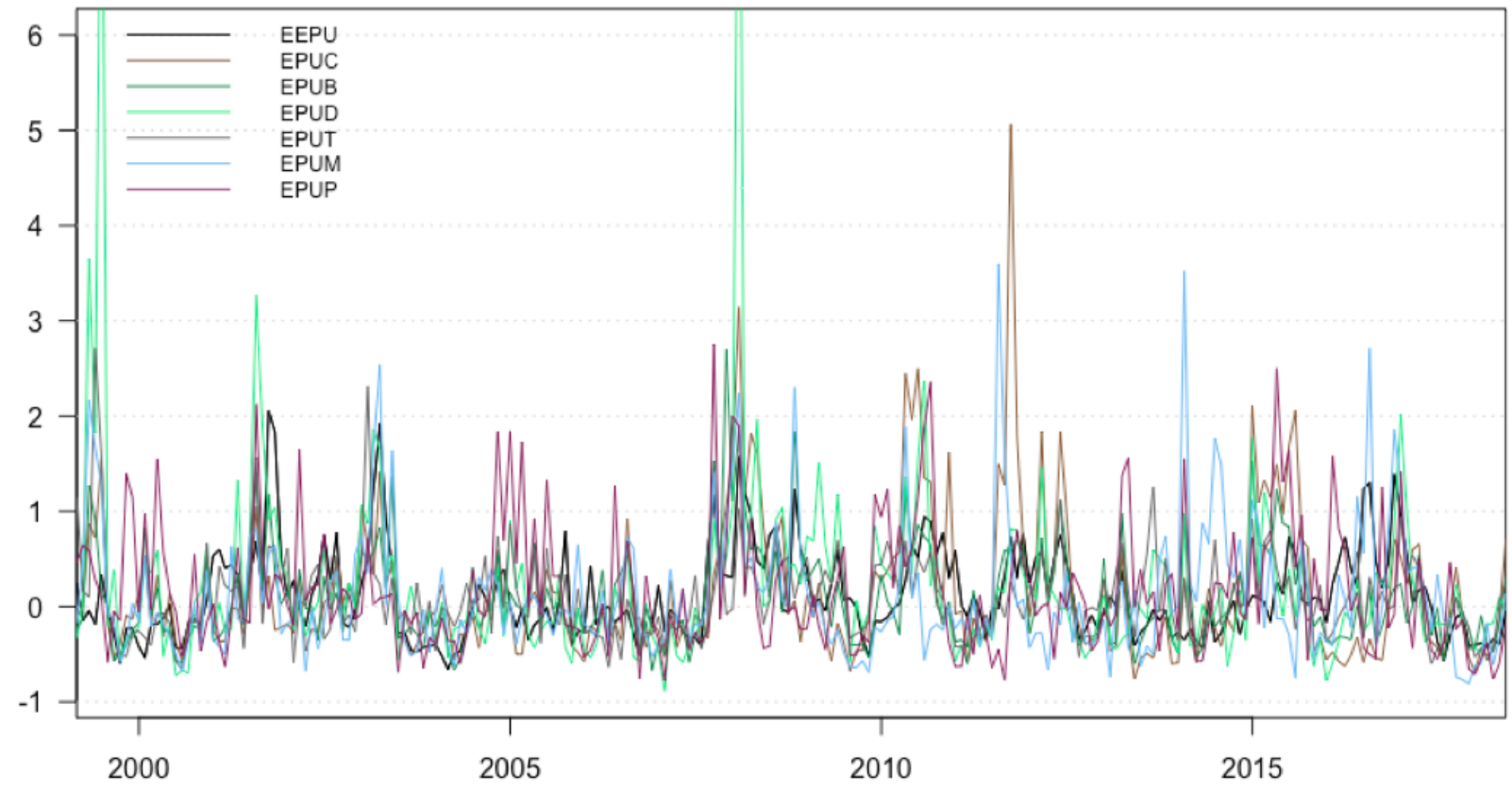

Notes: EEPU = European Economic Policy, EPUB = Banking Policy, EPUC = Currency Policy, $\mathrm{EPUT}=$ Tax Policy, EPUD $=$ Debt Policy, EPUP $=$ Pension Policy and EPUM $=$ Monetary Policy Uncertainty. 
Figure 3: Dynamic Total Connectedness

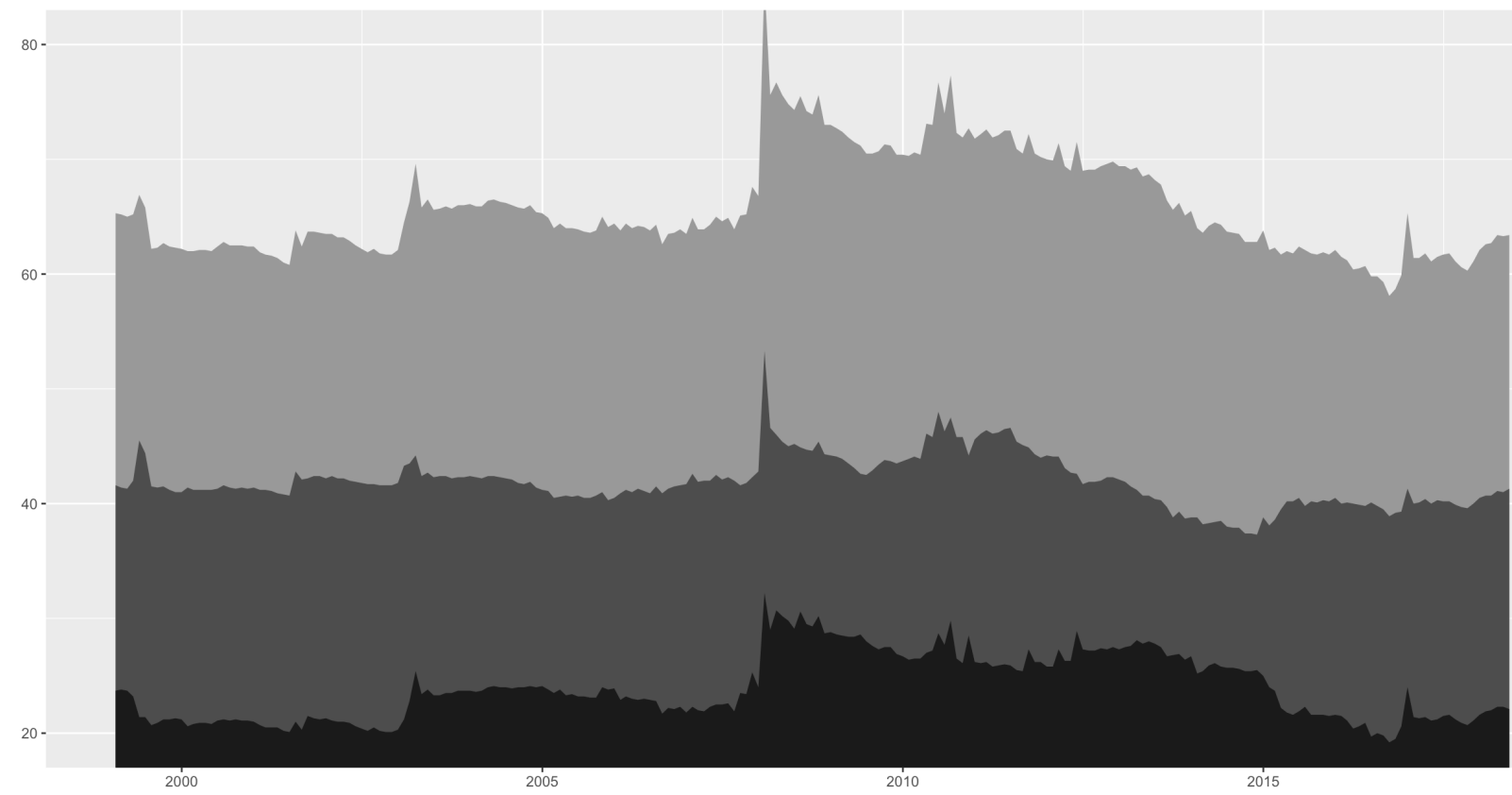

Notes: The light grey shaded area illustrates the TCI with external spillovers, while the dark grey area illustrates the TCI without external spillovers, and the black shaded area illustrates the international TCI.

Figure 4: Net Total Directional Connectedness
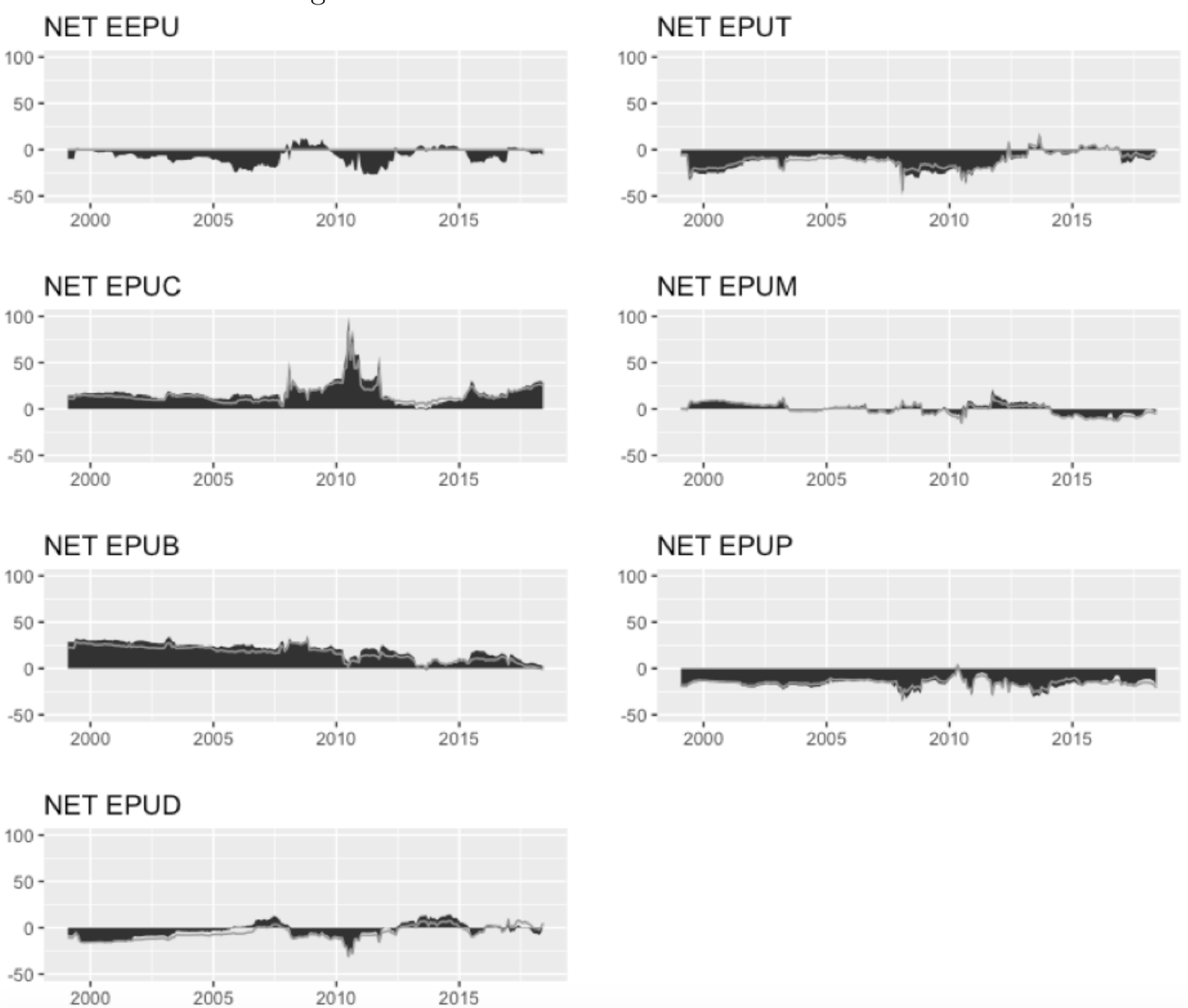

Notes: The black shaded area illustrates connectedness with external spillovers, whereas the grey line illustrates the internal spillovers. EEPU = European Economic Policy, EPUB = Banking Policy, EPUC = Currency Policy, $\mathrm{EPUT}=$ Tax Policy, EPUD $=$ Debt Policy, EPUP $=$ Pension Policy and EPUM $=$ Monetary Policy Uncertainty. 
Figure 5: External Net Pairwise Directional Connectedness

NET EEPU-EPUC

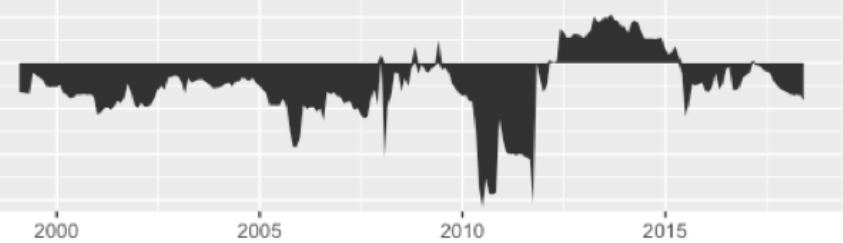

NET EEPU-EPUD

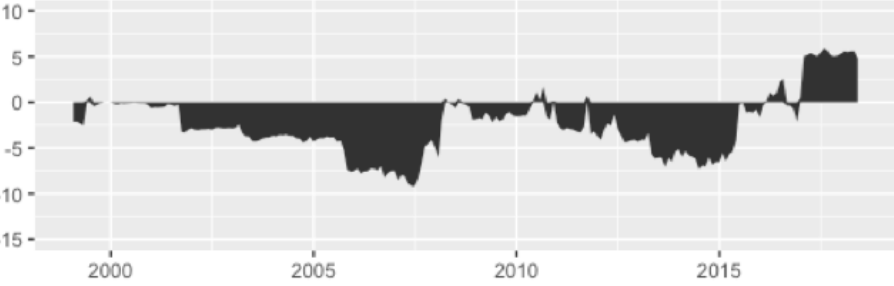

NET EEPU-EPUM

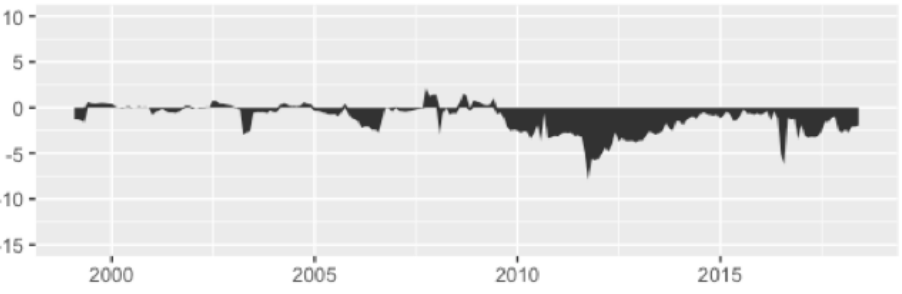

NET EEPU-EPUB

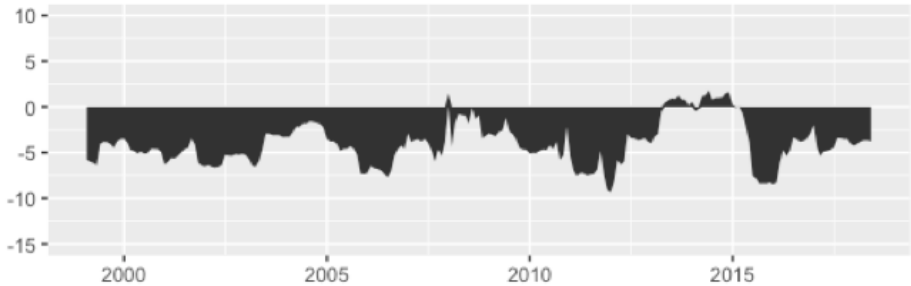

NET EEPU-EPUT

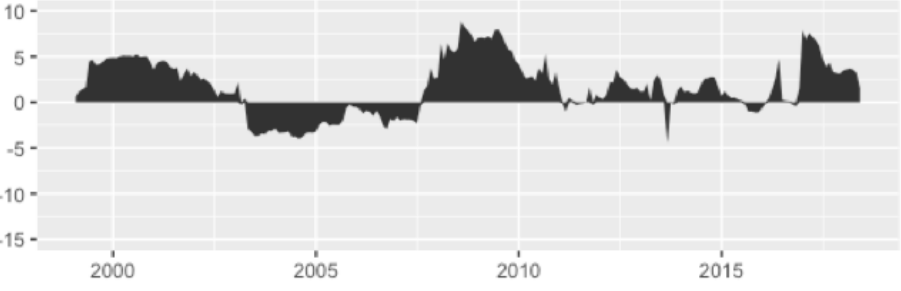

NET EEPU-EPUP

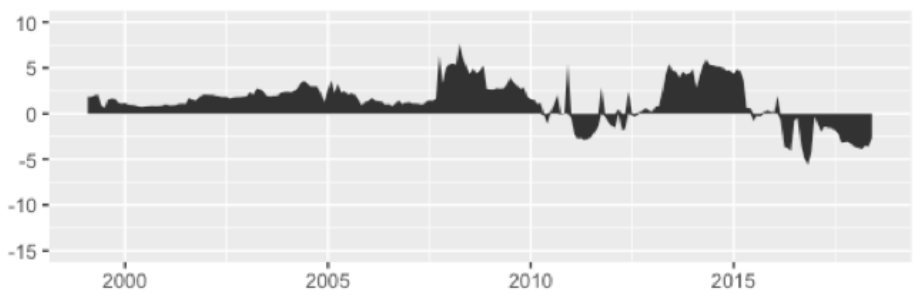

Notes: EEPU $=$ European Economic Policy, EPUB = Banking Policy, EPUC = Currency Policy,

$\mathrm{EPUT}=$ Tax Policy, EPUD $=$ Debt Policy, EPUP $=$ Pension Policy and EPUM $=$ Monetary Policy Uncertainty.

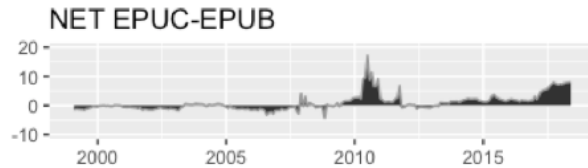

Figure 6: Internal Net Pairwise Directional Connectedness
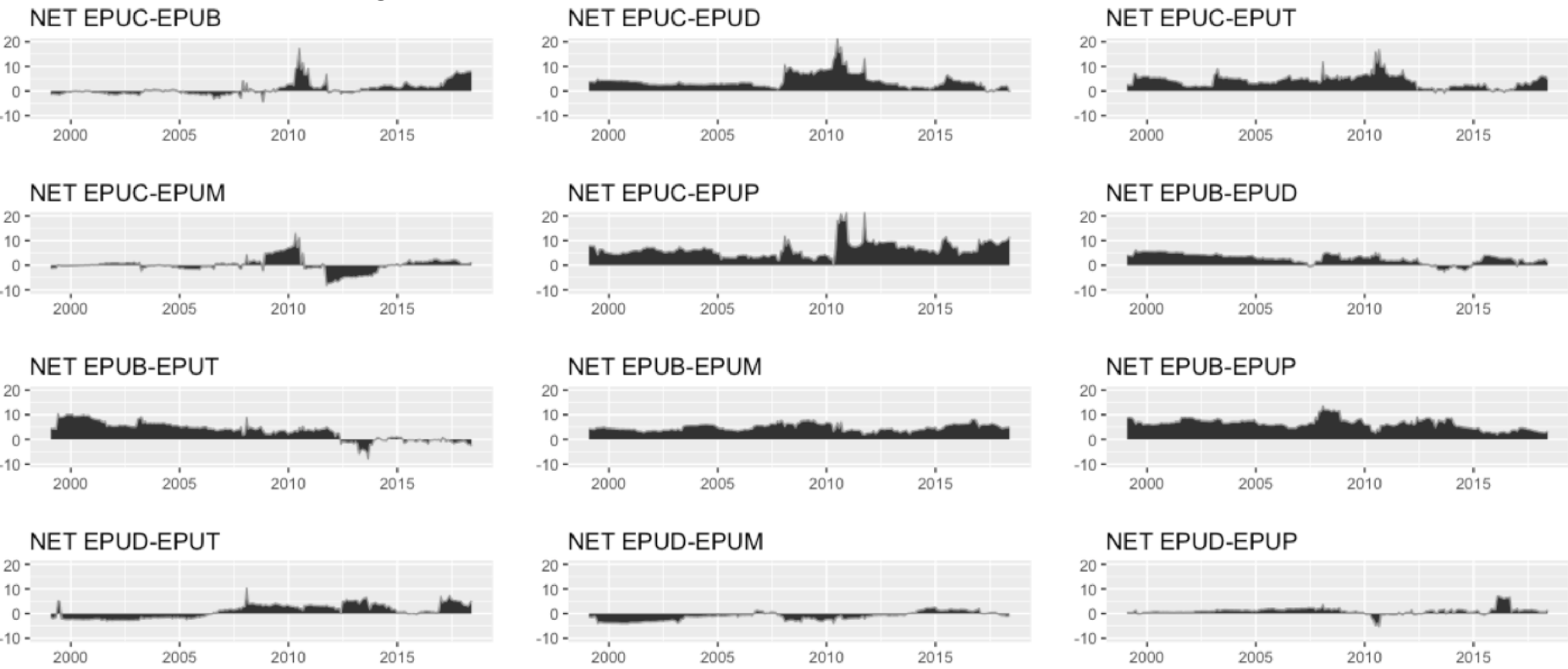

\section{NET EPUT-EPUM}

NET EPUT-EPUP
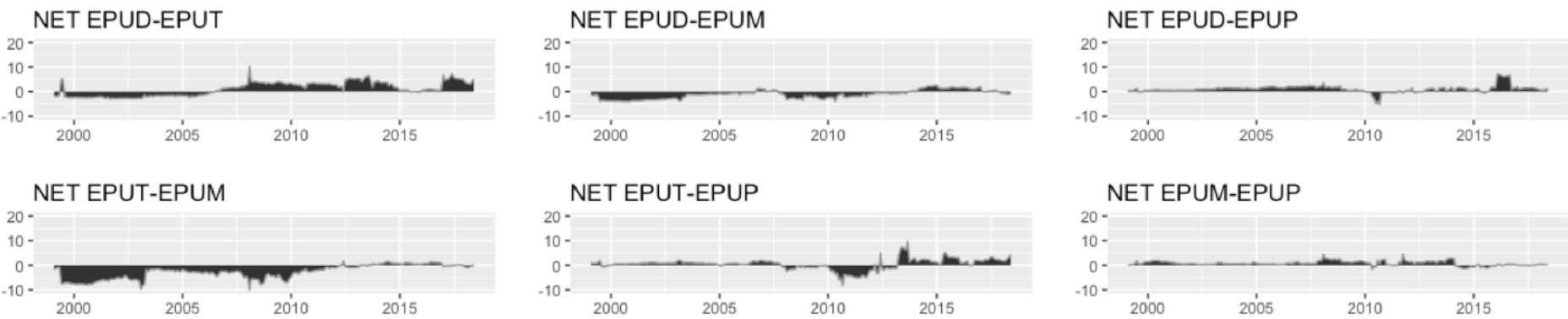

Notes: EEPU = European Economic Policy, EPUB = Banking Policy, EPUC = Currency Policy,

$\mathrm{EPUT}=$ Tax Policy, EPUD $=$ Debt Policy, EPUP $=$ Pension Policy and EPUM $=$ Monetary Policy Uncertainty. 
Figure 7: Net External Connectedness

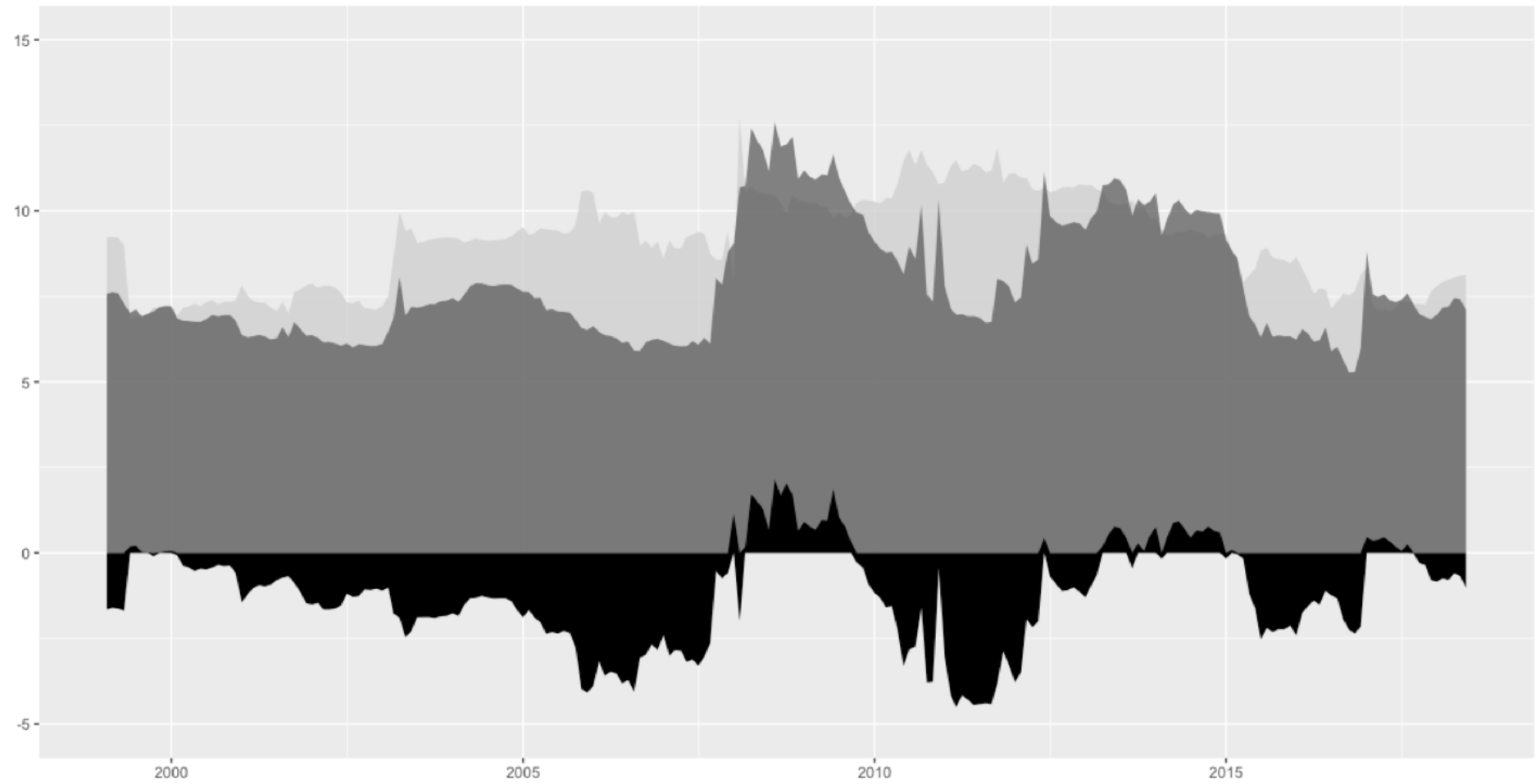

Notes: The light-grey shaded area illustrates dynamic international spillovers from Greece to Europe, the dark-grey shaded area shows dynamic international spillovers from Europe to Greece and the black area represents net international spillovers from Europe to Greece. 
Figure 8: Generalized Impulse Responses

EPUC-EEPU

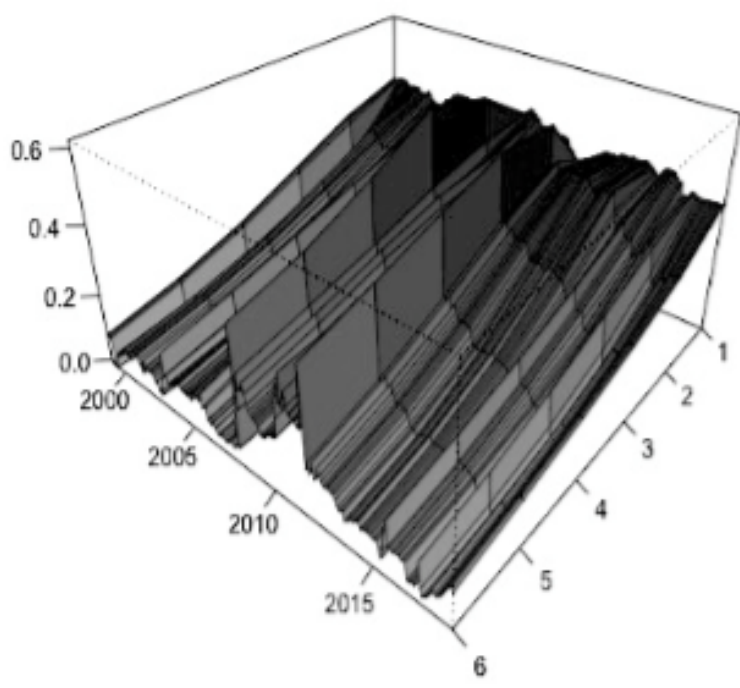

EPUC-EPUB

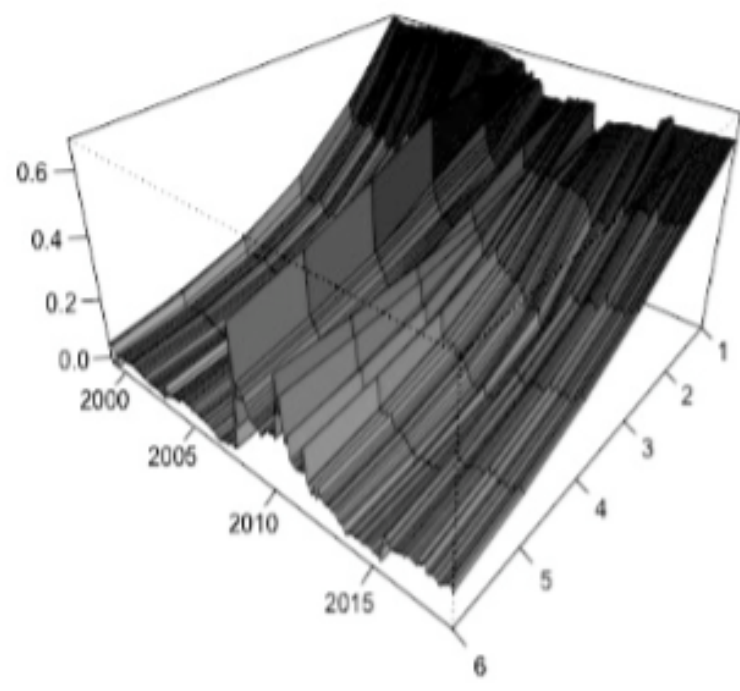

EPUC-EPUP

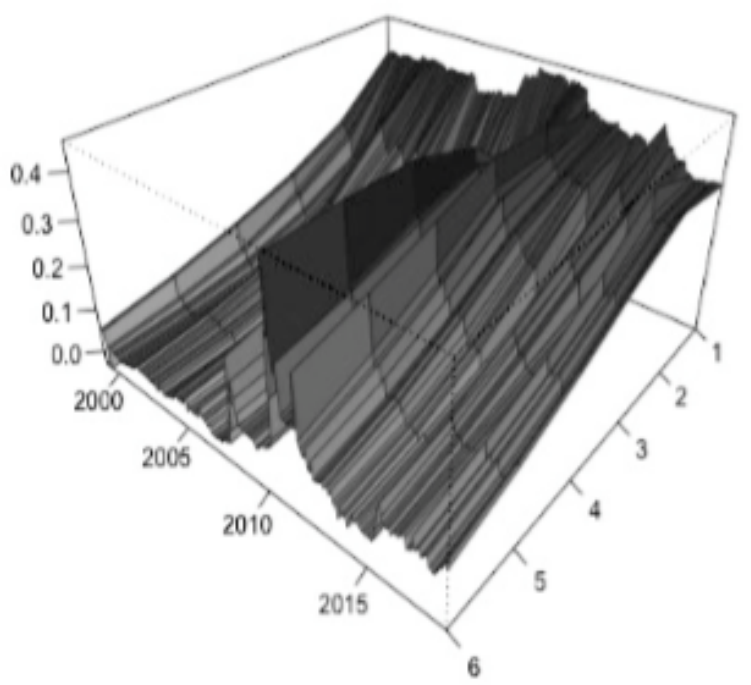

EPUB-EEPU

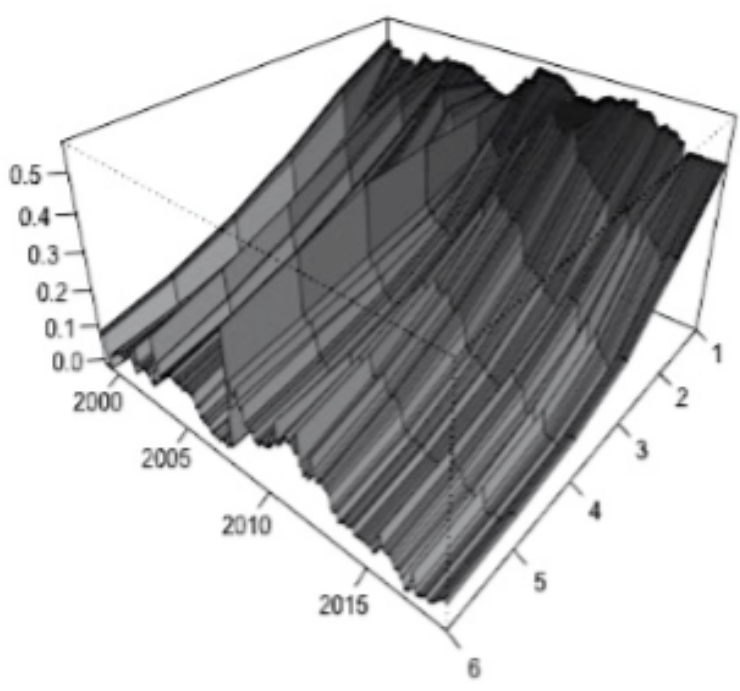

EPUB-EPUC

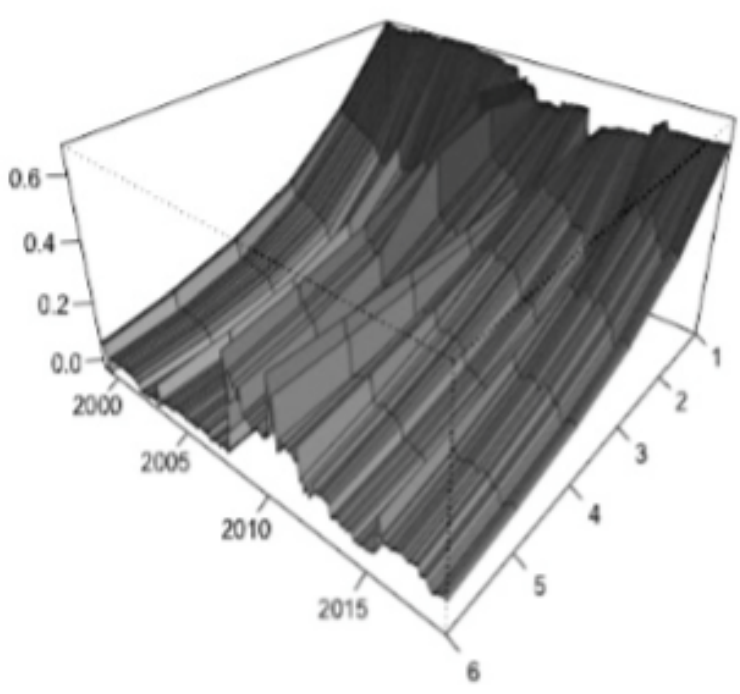

EPUM-EPUC

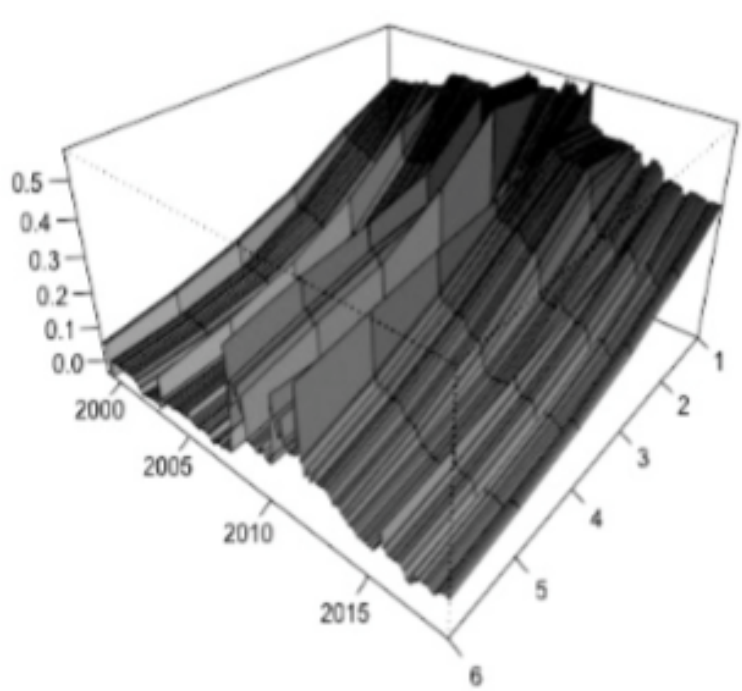

Notes: EEPU $=$ European Economic Policy, EPUB $=$ Banking Policy, EPUC $=$ Currency Policy, EPUP $=$ Pension Policy and $\mathrm{EPUM}=$ Monetary Policy Uncertainty. 


\section{A.1 Appendix}

The TVP-VAR which is applied in this study can be represented as follows,

$$
\begin{array}{rlrl}
\boldsymbol{y}_{t} & =\boldsymbol{\Phi}_{t} \boldsymbol{y}_{t-1}+\boldsymbol{\epsilon}_{t} & \boldsymbol{\epsilon}_{t} \mid \boldsymbol{\Omega}_{t-1} & \sim N\left(\mathbf{0}, \boldsymbol{\Sigma}_{t}\right) \\
\operatorname{vec}\left(\boldsymbol{\Phi}_{t}\right) & =\operatorname{vec}\left(\boldsymbol{\Phi}_{t-1}\right)+\boldsymbol{\xi}_{t} & \boldsymbol{\xi}_{t} \mid \boldsymbol{\Omega}_{t-1} \sim N\left(\mathbf{0}, \boldsymbol{\Sigma}_{t}^{\Phi}\right)
\end{array}
$$

For the initialization of the Kalman, we are using an empirical Bayes prior, where the parameters $v e c\left(\boldsymbol{\Phi}_{0}\right)$ and $\boldsymbol{\Sigma}_{0}$, are set equal to the estimation results of a constant parameter VAR based on the first 100 months.

$$
\begin{aligned}
\operatorname{vec}\left(\boldsymbol{\Phi}_{0}\right) & \sim N\left(\operatorname{vec}\left(\boldsymbol{\Phi}_{O L S}\right), \boldsymbol{\Sigma}_{O L S}^{\Phi}\right) \\
\boldsymbol{\Sigma}_{0} & =\boldsymbol{\Sigma}_{O L S} .
\end{aligned}
$$

The Kalman Filter estimation relies on forgetting factors $\left(0 \leq \kappa_{i} \leq 1\right)$ which regulates how fast the parameters are varying over time. Based on the sensitivty analysis of Koop and Korobilis (2014), we set $\kappa_{i}$ equal to $0.99^{2}$ and start with:

$$
\begin{aligned}
\operatorname{vec}\left(\boldsymbol{\Phi}_{t}\right) \mid \boldsymbol{y}_{1: t-1} & \sim N\left(\operatorname{vec}\left(\boldsymbol{\Phi}_{t \mid t-1}\right), \Sigma_{t \mid t-1}^{\Phi}\right) \\
\operatorname{vec}\left(\boldsymbol{\Phi}_{t \mid t-1}\right) & =\operatorname{vec}\left(\boldsymbol{\Phi}_{t-1 \mid t-1}\right) \\
\boldsymbol{\Xi}_{t} & =\left(1-\kappa_{2}^{-1}\right) \boldsymbol{\Sigma}_{t-1 \mid t-1}^{\Phi} \\
\boldsymbol{\Sigma}_{t \mid t-1}^{\Phi} & =\boldsymbol{\Sigma}_{t-1 \mid t-1}^{\Phi}+\boldsymbol{\Xi}_{t} \\
\hat{\boldsymbol{\epsilon}}_{t} & =\boldsymbol{y}_{t}-\boldsymbol{\Phi}_{t \mid t-1} \boldsymbol{y}_{t-1} \\
\boldsymbol{\Sigma}_{t} & =\kappa_{1} \boldsymbol{\Sigma}_{t-1 \mid t-1}+\left(1-\kappa_{1}\right) \hat{\boldsymbol{\epsilon}}_{t}^{\prime} \hat{\boldsymbol{\epsilon}}_{t}
\end{aligned}
$$

$\operatorname{vec}\left(\boldsymbol{\Phi}_{t}\right)$ and $\boldsymbol{\Sigma}_{t}^{\Phi}$ are updated by

$$
\begin{aligned}
\operatorname{vec}\left(\boldsymbol{\Phi}_{t}\right) \mid \boldsymbol{y}_{1: t} & \sim N\left(\operatorname{vec}\left(\boldsymbol{\Phi}_{t \mid t}\right), \boldsymbol{\Sigma}_{t \mid t}^{\Phi}\right) \\
\operatorname{vec}\left(\boldsymbol{\Phi}_{t \mid t}\right) & =\operatorname{vec}\left(\boldsymbol{\Phi}_{t \mid t-1}\right)+\boldsymbol{\Sigma}_{t \mid t-1}^{\Phi} \boldsymbol{y}_{t-1}^{\prime}\left(\boldsymbol{\Sigma}_{t}+\boldsymbol{y}_{t-1} \boldsymbol{\Sigma}_{t \mid t-1}^{\Phi} \boldsymbol{y}_{t-1}^{\prime}\right)^{-1}\left(\boldsymbol{y}_{t}-\boldsymbol{\Phi}_{t \mid t-1} \boldsymbol{y}_{t-1}\right) \\
\boldsymbol{\Sigma}_{t \mid t}^{\Phi} & =\boldsymbol{\Sigma}_{t \mid t-1}^{\Phi}+\boldsymbol{\Sigma}_{t \mid t-1}^{\Phi} \boldsymbol{y}_{t-1}^{\prime}\left(\boldsymbol{\Sigma}_{t}+\boldsymbol{y}_{t-1} \boldsymbol{\Sigma}_{t \mid t-1}^{\Phi} \boldsymbol{y}_{t-1}^{\prime}\right)^{-1}\left(\boldsymbol{y}_{t-1} \boldsymbol{\Sigma}_{t \mid t-1}^{\Phi}\right)
\end{aligned}
$$

Finally, we update the variance-covariance matrix, $\Sigma_{t}$, by:

$$
\begin{aligned}
\hat{\boldsymbol{\epsilon}}_{t \mid t} & =\boldsymbol{y}_{t}-\boldsymbol{\Phi}_{t \mid t} \boldsymbol{y}_{t-1} \\
\boldsymbol{\Sigma}_{t \mid t} & =\kappa_{1} \boldsymbol{\Sigma}_{t-1 \mid t-1}+\left(1-\kappa_{1}\right) \hat{\boldsymbol{\epsilon}}_{t \mid t}^{\prime} \hat{\boldsymbol{\epsilon}}_{t \mid t}
\end{aligned}
$$

\footnotetext{
${ }^{2}$ Even tough we could allow the forgetting factors to vary over time we have chosen to fix it to a constant value. The main reasons are retrieved from Koop and Korobilis (2013) who argue that the value added to the forecasting performance is questionable and that computation burden is increased significantly.
} 